\title{
Developing an intervention to promote person-centred care to improve management of behaviours that challenge among people living with dementia
}

\author{
Niyah Campbell \\ University of Birmingham \\ Kirsty Killick \\ Edinburgh Napier University \\ Nichola Seare \\ Aston University \\ lan Maidment \\ Aston University
}

Rachel Shaw ( $\nabla$ r.l.shaw@aston.ac.uk)

Aston University https://orcid.org/0000-0002-0438-7666

\section{Research article}

Keywords: dementia, challenging behaviour, person-centred care, medication review, behaviour change

Posted Date: January 22nd, 2020

DOI: https://doi.org/10.21203/rs.2.21504/v1

License: @ (i) This work is licensed under a Creative Commons Attribution 4.0 International License. Read Full License 


\section{Abstract}

Background: This paper reports the development work conducted for a feasibility study (MEDREV) conducted in the UK evaluating: (i) a medication review to reduce the prescription of psychotropic medication for managing behaviours that challenge among people living with dementia: and (ii) a training intervention for care home staff designed to improve the management of behaviours that challenge without medication using person-centred care. This paper reports the development of (ii) the training intervention for care home staff.

Methods: The intervention development was informed by the MRC guidelines for complex interventions and the phases of the Behaviour Change Wheel. We used an iterative approach responding to and consultations with stakeholders throughout the process.

Results: The target behaviours of the intervention were: responding to challenging behaviour as an expression of unmet need; communicating with compassion. The intervention was required to educate about psychotropics and their side-effects, to help care staff relate to people with dementia as individuals with individual needs and wants, to reflect upon how one might deliver the values of person-centred care in care scenarios, and to promote good team communication and self-care. An interactive, brief, in-house training session was developed with a number of recommendations for systemic change.

Conclusions: The intervention was developed in a systematic way taking into account the particularities of the care home context and the target population. These factors prompted many challenges as did the manner in which residential care home interventions are funded in the UK. An ideal intervention package would have incorporated environmental elements, more systemic support from the care home management, and more financial investment to offer a more detailed, longer lasting training intervention.

\section{Background}

This paper reports the intervention development phase of a feasibility study in the UK designed to reduce the prescription of psychotropic medication as a means of managing challenging behaviour for people living with dementia in care homes [1,2]. Challenging behaviour, also known as behaviours that challenge (terms will be used interchangeably), can include agitation, wandering, shouting, biting, aggression, and have been defined as:

"any behaviour by patients that is deemed to be dangerous to themselves, their fellow residents, and staff, or is considered antisocial within the environments where those patients have to coexist with others on a long term basis" (p.741) [3]

Psychotropic drugs have been used to manage these behaviours because they act as mood altering drugs. They include a range of antipsychotics, sedatives, antidepressants, mood stabilisers, and hypnotics. The UK National Dementia Strategy [4] estimated that 180,000 people with dementia were prescribed antipsychotics and that they were implicated in the deaths of 1,800 each year, despite only $20 \%$ of them benefiting from the antipsychotics [4]. This recommendation was echoed in the later report by the Royal Pharmaceutical Society in the UK [5], in which a key recommendation was to train care staff in non-pharmacological treatments for people with dementia displaying behaviours that challenge. However, targeting antipsychotics may lead to 
prescription of other psychotropic medications associated with serious side-effects; a recent Cochrane Review recommended that interventions be developed to reduce all psychotropic medication for the management of challenging behaviour [6].

Andrews [3] argued that the historic use of chemical and physical restraints as a first line response to challenging behaviour needs to be replaced by person-centred care. This is a key recommendation from the Banerjee Report to the UK Department of Health:

"There is a need to develop a curriculum for the development of appropriate skills for care home staff in the non-pharmacological treatment of behavioural disorder in dementia, including the deployment of specific therapies with positive impact. Senior staff in care homes should have these skills and the ability to transfer them to other staff members in care homes." [7] (page 9).

A response to this call for a curriculum already existed in the form of the seminal of Tom Kitwood [8] and later applications, in particular the work of Dawn Brooker [9]. Brooker developed the VIPS framework which identified the following as the core components of person-centred care: $V$ : valuing the person, I: individualized care, $P$ : perspective of the person, and S: social environment. This offered a tangible interpretation of nonpharmacological, person-centred care strategies that could be used instead of psychotropic medication to manage behaviours that challenge. Thus, the VIPS would provide care home staff with practical applications of person-centred care principles.

The shift toward the provision of behavioural and educational training for care staff, and away from psychotropic medication as a first line defence, has been echoed in a systematic review which emphasised the importance of taking the time to make a decision on a case-by-case basis in antipsychotic prescribing [10]. Nevertheless, there are challenges to adopting this approach. Both in residential care homes and in primary care resources are lacking to fully support this change in practice toward a different kind of care that involves building relationships and tailored strategies for each individual with dementia [11]. Although staff training does show promise, there are limitations in the poor quality of studies and lack of significant effects [12-15]. The focus of future training programmes therefore needs to build upon previous findings: educational training about dementia and building self-confidence to work with residents with dementia through exposure can help to create positive relationships and therefore better care [16]; if staff engage in problem-solving behaviours and reflective practice they will be better equipped to develop strategies to manage behaviours that challenge that are appropriate for individual residents [15]; but person-centred care can be vulnerable to systemic constraints, meaning managerial buy-in and organisational support are essential to its success $[13,17]$.

The objective of our feasibility study was to trial an intervention that would (i) review medication with a view to reducing psychotropics as a means of managing behaviours that challenge and (ii) prepare care staff to provide non-pharmacological treatments for managing those challenging behaviours in the form of personcentred care. This paper reports the process of developing (ii) the training intervention for care staff.

\section{Methods}

The Medical Research Council (MRC) guidelines for complex interventions [18] informed our iterative and collaborative approach to developing this intervention. The study took place in the West Midlands region of 
England, UK. Five care homes with more than 40 residents, including residents with dementia, were recruited to take part. Ethical approval was gained (Health Research Authority: 15/EM/0314; host university: \#789) to recruit stakeholders as researcher-participants $(n=16)$ to represent the following: managerial $(n=4)$ and care staff $(n=4)$ from residential care homes, general practitioners (GPs) $(n=1)$, psychiatrists $(n=1)$, clinical psychologists $(n=2)$, community psychiatric nurses $(n=2)$, researchers working in care homes $(n=1)$, and relatives of someone living with dementia $(n=1)$. Researcher-participants were invited to individual interviews or group discussions. All selected individual interviews either face-to-face or be telephone (30-90 minutes) except for the clinical psychologists and community psychiatric nurses who were met in person in two groups of two (approx. 90 minutes each). In addition, the researchers had already gained detailed data from community pharmacists in a previous study to add to this pool of knowledge and expertise [19]. This sample was not representative as such, but it did reflect the different professionals involved in residential dementia care in the English Health Service.

The bulk of data collection took place in the initial stages of identifying the target behaviour and the potential contents of the intervention. A semi-structured schedule was used, including questions such as: to managers, psychiatrists, clinical psychologists, community psychiatric nurses - 'what kind of content do you think is required to train care staff to deal more effectively with behaviours that challenge without using psychotropic medication?'; to care home staff: 'would you do anything differently when caring for people with challenging behaviours if you didn't have access to psychotropic medication?" to GPs - "what role do you play in the care of people with dementia?'; to all - are you aware of the current best practice guidelines for the use of psychotropic medication for the management of behaviours that challenge?'.

Data collection stopped when no new ideas or additional information was provided. Researcher-participants were consulted further by telephone and/or email as the research team worked through the stages of development described below. This collaboration of researcher-participants helped validate the proposed elements of the intervention and the iterative approach meant we were able to make changes following these consultations. This sample was not involved in the evaluation of the intervention, reported separately [2].

To ensure a rigorous process, we followed the stages of the Behaviour Change Wheel [20] to develop our intervention. The Behaviour Change Wheel is a practical guide for developing behavioural and/or psychological interventions that is informed by the health psychology theory of behaviour change, COM-B.[21] The guide includes very clear instructions for each stage of development and includes worksheets that individuals can use in their own work (these are reproduced in their completed in Tables 1-5 to illustrate the processes involved in this study).

The first step was to define the problem in behavioural terms, i.e. identify the behaviour that we wanted to change. Then we engaged in a behavioural analysis, informed by the COM-B model [20]. The COM-B model distils behaviour into its constituents and considers them within their context [20]. In the model, the antecedents of Behaviour are Capability, Opportunity, and Motivation. Each of these is context-specific and requires careful attention in order to fully expose the nature of behaviour one wishes to target for change. The $C O M-B$ mode/ provided the structure for a behavioural analysis to define the target behaviour and conduct a behavioural analysis. We did this by coding data from interviews and discussions with stakeholders using the COM-B model. 
Following the behavioural analysis, we explored the functions required in the intervention to achieve the target behaviour change, e.g. would it need to educate, support, or provide models of behaviour? We then identified the appropriate Behaviour Change Techniques, identified in systematic reviews of psychological behaviour change interventions, [22] that would help us achieve these functions. Finally, we applied the APEASE criteria [21] by assessing: affordability, practicability, effectiveness and cost-effectiveness, acceptability, sideeffects/safety, and equity. An in-principle APEASE analysis only was possible because as an intervention for a feasibility study, we were only able to consider some of the criteria in theory rather than in practice. For example, without a full trial it was not possible to fully assess affordability, effectiveness or costeffectiveness. We were, however, able to assess acceptability, side-effects/safety, and equity.

\section{Results}

Our first challenge was to frame the problem in behavioural terms. The review of the literature, best practice guidelines, findings from interviews and discussions with researcher-participants, found the problem to be multifaceted: psychotropic medications are being used as a first line response to managing challenging behaviours among care home residents with dementia; care home staff do not understand the risks of psychotropics; although many care home staff were aware of person-centred care, they did not conceptualise it as a non-pharmacological treatment for managing behaviours that challenge and so did not see it as an alternative to medication; and although aware in principle of person-centred care, it was not always used in everyday practice. We turned to the literature and best practice guidelines to begin to explore ways in which these issues have been understood and what recommendations for practice have been made.

A useful overview of work on psychosocial (i.e. non-pharmacological) interventions for dementia care for the treatment of challenging behaviours was the pan-European project, INTERDEM [26,27]. The INTERDEM project identified and appraised the quality of existing expert guidance across Europe.

In the INTERDEM review, the UK guideline produced jointly by the National Institute for Health and Care Excellence (NICE) and the Social Care Institute for Excellence (SCIE), Dementia: supporting people with dementia and their carers in health and social care, first published in 2006 and updated in 2017 [28], was judged highest in quality across all domains and so was ideal to inform our intervention. Other UK guidance was also identified, which stems from the same evidence base and offers the same key messages: first published in 2013 and updated in 2017, The Dementia Guide[29], and Common Core Principles for Supporting People with Dementia [4].

The NICE and SCIE guidance [28] recommended staff training in person-centred care and outcome-focused care for people living with dementia. While such guidance enables us to identify priorities, it does not express the problem behaviourally. To seek a behavioural focus we explored literature that has attempted to operationalise the concepts underpinning person-centred care. A good example available at the time came from Passalacqua \& Harwood's [14] extension of Dawn Brooker's VIPS [9]. Their training programme offered concrete examples of communicative strategies demonstrating Valuing the person, Individualised care, focusing on the Perspective of the person with dementia, and the Social environment and increased care staff's empathy toward and hope for those living with dementia. Following their training, Passalacqua \& 
Harwood showed less depersonalisation of residents living with dementia and more time was spent to engage residents in leisure activities that were important to them. Something that was supported by our stakeholders:

"An activity can be something as simple as painting somebody's nails, giving somebody a hand massage, looking through a reminiscence book on a one-to-one. We are trying to get [care staff] to do more one-toone interaction that is more meaningful to that individual and doing lots of life history work." (community psychiatric nurse)

\section{Defining the Target Behaviour}

We were now getting closer to a behavioural focus, i.e. what behaviours care staff need to employ in order to deliver person-centred care. To further explicate this, we examined the literature to specify the target behaviour as precisely as possible.

A number of systematic reviews were identified which provided a synthesis of the evidence base $[6,12,21,22]$. O'Connor et al.'s [12] summary of the paradigms which have historically informed the development of interventions to improve the management of challenging behaviours was helpful in judging different kinds of approaches. The $A B C$ model (antecedents, behaviours, consequences) seeks to reinforce appropriate behaviours and discourage less helpful ones, drawing on the Social Learning Theory [23,24]. The unmet needs hypothesis states that challenging behaviours stem from unmet human physical, emotional or social needs [21]. The unmet needs hypothesis was supported by our stakeholders:

"We very much look at every person as an individual and every behaviour, there is a reason behind that behaviour. So it's looking for that reason and trying to connect and understand that that behaviour has happened." (care home manager)

The stress threshold model suggests that dementia reduces a person's ability to tolerate stress, which results in inappropriate behaviour [25]. This work helped us conceptualise part of the problem - the need to re-frame care staff's understanding of the antecedents of challenging behaviour and in turn their perceptions of people with dementia.

The unmet needs hypothesis resonated across best practice guidelines and findings from interviews and discussions with researcher-participants. Alongside this, there was an emphasis in interviews and discussions on communicating with compassion as a founding principle of person-centred care. We therefore considered both responding to challenging behaviour as an unmet need and communicating with compassion as potential target behaviours for our intervention (see Tables 1-2).

This exercise enabled us to translate the concepts into actions, e.g. problem-solving, using distraction techniques, and it helped us realise the potential impact of changing this behaviour; if care staff were able to change every interaction with residents and behave in a person-centred way at all times, this would have a hugely positive impact on the residents' wellbeing and could potentially provide a successful alternative to psychotropics as a way of managing challenging behaviour [22].

The behaviours identified to achieve compassionate communication were clear across the systematic reviews and guidance documents cited above, but were best illustrated by Passalacqua \& Harwood's [14] adaptation 
of Brooker's VIPS [9]. We contacted these authors to obtain the video material used in their training which clearly demonstrated the significance of eye contact, direct communication, and not ignoring the resident. This helped us delineate some of the likely content in our intervention.

\section{Behavioural Analysis and 'Diagnosis'}

In order to develop an intervention that would have a chance of being effective at changing behaviour, our next step was to understand the precursors of behaviour in order to identify ways that we might be able to intervene to change behaviour. This took the form of a behavioural analysis [20]. We did this by coding data from stakeholder interviews and discussions using the COM-B model. We then compared this coding to recommendations in the literature and best practice guidelines. The results of this process are reported in Tables 3-4.

Table 3 unpacks the target behaviour - responding to challenging behaviour as an unmet need. It was clear from the literature that resource investment was required for person-centred care to be implemented [11] and so in terms of physical Capability, this target behaviour required staff to have stamina for long, emotionally intense working hours and from consultations with stakeholders it was clear that changes to shift patterns were unlikely to change. Support from the organisation in the form of regular breaks, supervision, good working conditions was required. Generating the psychological Capability of staff meant providing them with information and skills to boost their knowledge and understanding of dementia and the use of psychotropics as well as person-centred care. Physical and social Opportunities required buy-in from managers to ensure materials were available for initiatives such as about me books, and to ensure that responding to challenging behaviour as an unmet need became a normalised way of dealing with it across care staff. Reflective Motivation required staff to become self-aware and for that to translate to automatic Motivation staff would need to want to believe in the notion that challenging behaviour is an expression of unmet need thereby taking ownership of this idea.

Table 4 outlines the behavioural analysis of communicating with compassion. In a literal sense, staff already have the physical Capability to communicate with staff, but adding compassion to that communication may require a change for some individuals. Some staff may already have psychological Capability in principle, especially if they have received training on person-centred care, caring with dignity, and so on, but they may still require a refresher. Others may not have received training and so will need to boost their knowledge and understanding of how good communication skills can improve the wellbeing of residents with dementia. To create the physical Opportunity the staff need space and time to reflect on their communication with residents. This is contingent upon the social Opportunity which would endorse this reflective behaviour if it became normal practice to share things that worked well in positive interactions, for example. Reflective Motivation requires staff to be self-aware and to separate the person from the condition in order to behave compassionately toward them. For that Motivation to become automatic, care staff need to be personally invested in the benefits of communicating compassionately with residents.

To summarise, the behavioural 'diagnosis' was as follows:

- To achieve our goal that care staff would respond to challenging behaviour as an expression of an unmet need we needed to facilitate the use of problem-solving techniques to help care staff determine the 
underlying needs of people with dementia that may result in challenging behaviour.

- To do this, we would need care staff to understand this principle.

- We would also need to demonstrate that using tailored distraction techniques, which can reduce stress levels among people with dementia, may help to prevent behaviours that challenge.

- For our intervention to achieve the goal of care staff communicating with compassion, we would need them to have good working conditions with opportunities for reflection and discussion with managers and colleagues.

- Furthermore, we would need them to understand the benefits of compassionate communication to residents.

\section{Identifying Intervention Functions}

All work to date, reviewing the literature and best practice guidelines, interviews with stakeholder researcherparticipants, and going through the stages of the Behaviour Change Wheel pointed to the intervention having a Training function; it was clear that we would need to impart skills. The training would also need to be Educational because it was clear from our interviews with stakeholders that care staff were not knowledgeable about the side-effects of psychotropics, the recommendation that challenging behaviours were better treated with non-pharmacological (or psychosocial) treatments, or that person-centred care constitutes one such treatment. Due to the significance of generating the social Opportunity in achieving change to our target behaviours we deduced that our intervention would also need the functions of Modelling and Enablement. Our analyses pointed toward collective change, or rather individual behaviour change supported by role-modelling from peers and management (modelling) with the recruitment of VIPSchampions; and structured support from management in the form of supervision, handover meetings, training etc. (enablement).

\section{Selecting Behaviour Change Techniques}

In order to perform the functions outlined in the previous section we selected a number of Behaviour Change Techniques (BCTs) to integrate into our intervention [20]. As a training intervention, it was largely based on Shaping knowledge, especially Instructions on how to perform the behaviour of communicating with compassion. Shaping knowledge also involved providing Information about antecedents and Re-attribution, in relation to challenging behaviour as an expression of unmet need, the side-effects of psychotropics, and the recommendation to offer non-pharmacological interventions to manage challenging behaviour.

Key elements of the education provided involved Natural consequences - Information about health consequences to residents and care staff themselves from engaging in compassionate communication was included in the training as well as Information about social and environment consequences of better communication within care teams and among residents. Monitoring of emotional consequences was encouraged.

Social support was embodied in the intervention in a Practical sense, i.e. that it was group training and involved group activities. Staff were also encouraged to provide each other with Emotional social support both in the training and in practice. 
Once we had viewed the video material demonstrating Brooker's VIPS [9] developed by Passalacqua \& Harwood [14], we sought permission from the authors to use it in our own training. This formed the BCT, Comparison of behaviour through the Demonstration of the behaviour.

Working through the Behaviour Change Wheel brought us to realise that a fundamental characteristic of the training was that it was interactive and involved care staff role-playing their behaviours, thus engaging in Repetition and substitution - behavioural practice and rehearsal formed part of the intervention.

We also wanted to inspire Self-belief through Focus on past success as care workers, and Self-talk in small groups about their interactions with residents and how they made them feel.

\section{Assessing the APEASE Criteria}

Throughout the selection of these BCTs we had to keep in mind the APEASE criteria [21]: affordability, practicability, effectiveness and cost-effectiveness, acceptability, side-effects/safety, and equity. The affordability of the intervention was determined by the funding body (National Institute for Health Research, Research for Patient Benefit reference number: PB-PG-0613-31071). In projects funded this way, interventions require treatment costs to be provided by the appropriate National Health Service Trust, and in the case of primary care, funding decisions are made by regional Clinical Commissioning Group (CCG)[1]. This meant the training would be restricted to a one-off session lasting three hours.

The training was delivered on site in participating care homes and so worked well in a practical sense. We use the Maslach Burnout Inventory [30] and the Attitudes toward Dementia Questionnaire [31] to measure the effectiveness of the intervention. As a feasibility study, we were not able to fully assess the cost-effectiveness. Acceptability of the intervention was something we had prioritised from the start, which is a key reason we recruited stakeholders to help inform it. A central tenet of the intervention was to provide equitable care to people with dementia, but a likely side-effect was that all residents would receive an equitable level of personcentred care. We did not identify any risks to safety as the intervention was discussed in detail with care home managers and was found to meet safety policies.

\section{Description of the Intervention}

The major component of the intervention was the training session itself. This involved a three hour session with care staff which used powerpoint for information delivery and workbook for interactive exercises and role-play. Care staff were able to take a copy of the slides and workbook away with them. Stakeholder researcher-participants highlighted that there was a need for GPs to also receive this training. We therefore made it available to GPs in person or online.

We contemplated for some time what our training should be called. We wanted the title of the training to sum up the key message: Unmet needs are hidden inside; they are difficult to reveal to the outside world when communication skills are lacking; we need to access what is on the inside to understand what is going on outside. We therefore named our training, Inside Out. Indicative content of the slides is shown in Figure 1. The prominence of problem-solving skills in caring for people with dementia across literature and best practice guidelines also resonated with this name: to understand what is on the inside, care staff need to play the part 
of a detective to problem-solve the situation, to identify those hidden causes of challenging behaviour, and to use the residents' personal histories to develop ways of reducing or eradicating those triggers. This label also worked when considering self-care: care staff need to be aware of how they are feeling on the inside in order to prevent those feelings from showing on the outside in their interactions with residents.

Details of the training intervention are presented in Table 5.

Other materials included behavioural cues reiterating the central messages of the training to be posted on noticeboards and sent via email to staff. Meetings were also held with care home managers to encourage them to introduce the VIPS as an agenda item in team meetings and to raise the use of VIPS in supervision sessions.

\section{Discussion}

This paper has reported the development of an intervention using the Behaviour Change Wheel. The intervention was developed in response to a call $[4,5,7]$ to reduce psychotropic prescription as a means of managing challenging behaviour among people with dementia and to instead offer a non-pharmacological treatment. The main feasibility study [2] reported that delivering (i) the medication review across five care homes proved challenging and would require significant modification to be taken to full trial. Nevertheless, care home staff reported positive experiences of (ii) the training intervention and post intervention reported adopting a more person-centred approach [2]. The training intervention described here was therefore evaluated as feasible to deliver and, as reported in the feasibility study [2], it helped increase staff's ability and confidence to manage behaviours that challenge among residents with dementia without the need for medication.

The MRC [18], among others [32] have called for transparency in developing complex interventions as a way of explicitly evidencing the ingredients of an intervention and decisions about how it is delivered [33]. They also promoted the need to engage stakeholders in intervention development in order for it to meet the need and for it to be both acceptable and feasible within the intended context [18]. The Behaviour Change Wheel offered a methodology for structuring the process of intervention development to ensure all parties were considered, to ensure the intervention was evidence based, that was theoretically informed, and that it would be feasible for the target population. This helped us to develop an intervention fit for purpose. Rather than a 'brand new' intervention, Inside Out was created using a number of constituent parts including: recommendations to reduce psychotropic medication [5,7]; conceptualising challenging behaviour using the unmet need hypothesis [21]; applications of person-centred care for people with dementia [8,9]; best practice guidelines that suggest particular behaviours and training content [28]; and existing training materials [14].

Research conducted since this intervention was developed continues to promote the use of training, but it also warns of the need for investment $[10,11,34]$. Our Inside Out intervention has since been evaluated, and while there were limitations due to the small scope of the study, it was found to be acceptable and made an impact on the ways in which care staff approached residents with dementia [2].

There are always limitations when carrying out research of this kind. In this case, limitations arose from two main areas. First, the larger MEDREV study [2] was limited by how funds are allocated by the UK's National 
Institute for Health Research, Research for Patient Benefit programme. Mental health research in the UK is managed in primary care, which means funds are managed by Clinical Commissioning Groups (CCGs). The local CCG in this case supported minimal funding for the training intervention, which posed restrictions regarding the length of the training and the time researchers were able to spend in each care home. The behavioural analysis we conducted and consultations with stakeholders both pointed toward the need for sustained researcher presence in the care homes to further encourage behaviour change, but also to provide the environmental cues and social opportunities for it to occur. The second challenge was that the sample of stakeholders we recruited as researcher-participants was small and limited to a small region of England, UK. Although the recommendations made by stakeholders were corroborated by good practice guidance and by the literature, clearly further empirical research is required in other geographic areas meeting the demands of other care contexts for this staff training intervention to be fully tested.

If we were to do this work again, we would use the Template for Intervention Description and Replication (TIDieR) checklist [34] to ensure transparency and rigour in the work required to develop an intervention.

\section{Conclusions}

Documenting the development of healthcare interventions can increase transparency and increase the likelihood of successful implementation. The intervention we developed is evidence based and has been found to have a positive impact in a recent feasibility study. Further empirical work is required to test the intervention further and to promote investment in the residential care sector to continue this work.

\section{List Of Abbreviations}

BCW: Behaviour Change Wheel; BCT: Behaviour Change Techniques; GP: General Practitioner; MRC: Medical Research Council; VIPS: Valuing personhood, individual needs, personal perspective, social environment.

\section{Declarations}

Ethics approval and consent to participate

Ethical approval was granted by the Health Research Authority (15/EM/0314) and the host university.

Consent for publication

Not applicable.

Availability of data and material

The datasets generated and analysed during the current study are not publicly available due to the challenges of fully anonymising qualitative data generated in healthcare settings, but are available from the corresponding author on reasonable request.

Competing interests

Page $11 / 20$ 
The authors declare that they have no competing interests.

Funding

This research was funded by the National Institute for Health Research, Research for Patient Benefit programme, reference: PB-PG-0613-31071.

Authors' contributions

RLS led the intervention development with support from NC and KK. IDM was chief investigator of the feasibility study and invested time in the developmental stages and were involved in discussions as we moved through the stages of the Behaviour Change Wheel. RLS led the writing of the manuscript and all authors contributed and approved the final version.

\section{References}

1. Maidment ID, Shaw RL, Killick K, Damery S, Hilton A, Wilcock J, et al. Improving the management of behaviour that challenges associated with dementia in care homes: Protocol for pharmacy-health psychology intervention feasibility study. BMJ Open. 2016;6(3).

2. Maidment ID, Damery S, Campbell N, Seare N, Fox C, lliffe S, et al. Medication review plus person-centred care: a feasibility study of a pharmacy-health psychology dual intervention to improve care for people living with dementia. BMC Psychiatry [Internet]. 2018;1-11. Available from: https://bmcpsychiatry.biomedcentral.com/track/pdf/10.1186/s12888-018-1907-4 (accessed 22nd October 2018).

3. Andrews GJ. Managing challenging behaviour in dementia: a person centred approach may reduce the use of physical and chemical restraints. Br Med J. 2006;332:741.

4. Health D of. Common Core Principles for Supporting People with Dementia [Internet]. Dementia. 2011. Available from:

https://www.gov.uk/government/uploads/system/uploads/attachment_data/file/215562/dh_127587.pdf

5. Society RP. The right prescription: a call to action [Internet]. London; 2012. Available from: https://www.rpharms.com/Portals/0/RPS document library/Open access/Publications/The Right Prescription - inappropriate use of antipsychotics in dementia report.pdf

6. Declercq T, Petrovic M, Azermai M, R VS, Aim DS, MI VD. Withdrawal versus continuation of chronic antipsychotic drugs for behavioural and psychological symptoms in older people with dementia ( Review ). Cochrane Libr. 2013;(3).

7. Banerjee S. The use of antipsychotic medication for people with dementia: Time for action. Dep Heal [Internet]. 2009;60. Available from: http://s395229360.onlinehome.us/Research/Digest/NLPs/BanerjeeReportOnGeriatricNeurolepticUse.pdf

8. Kitwood T. Dementia reconsidered: the person comes first. Buckingham: Open University Press; 1997.

9. Brooker D. What is person-centred care in dementia? Rev Clin Gerontol. 2004;13(3):215-22.

10. Walshe $\mathrm{C}$. The evaluation of complex interventions in palliative care: An exploration of the potential of case study research strategies. Palliat Med. 2011;25(8):774-81. 
11. Jennings AA, Foley T, Mchugh S, Browne JP, Bradley CP. “Working away in that Grey Area..” A qualitative exploration of the challenges general practitioners experience when managing behavioural and psychological symptoms of dementia. Age Ageing. 2018;47(2):295-303.

12. O'Connor DW, Ames D, Gardner B, King M. Psychosocial treatments of psychological symptoms in dementia: a systematic review of reports meeting quality standards. Int Psychogeriatrics. 2009;21(2):241-51.

13. Spector A, Orrell M, Goyder J. A systematic review of staff training interventions to reduce the behavioural and psychological symptoms of dementia. Ageing Res Rev. 2013;12(1):354-64.

14. Passalacqua SA, Harwood J. VIPS Communication Skills Training for Paraprofessional Dementia Caregivers: An Intervention to Increase Person-Centered Dementia Care. Clin Gerontol. 2012;35(5):425-45.

15. Kuske B, Luck T, Hanns S, Matschinger H, Angermeyer MC, Behrens J, et al. Training in dementia care: a cluster-randomized controlled trial of a training program for nursing home staff in Germany. Int Psychogeriatrics. 2009;21(2):295-308.

16. Travers CM, Beattie E, Martin-Khan M, Fielding E. A survey of the Queensland healthcare workforce: attitudes towards dementia care and training. BMC Geriatr [Internet]. 2013;13:101. Available from: http://www.pubmedcentral.nih.gov/articlerender.fcgi? artid=3853034\&tool=pmcentrez\&rendertype=abstract

17. Visser SM, McCabe MP, Hudgson C, Buchanan G, Davison TE, George K. Managing behavioural symptoms of dementia: effectivess of staff education and peer support. Aging Ment Health. 2008;12(1):47-55.

18. Craig P, Dieppe P, Macintyre S, Michie S, Nazareth I, Petticrew M. Developing and evaluating complex interventions: the new Medical Research Council guidance. Bmj [Internet]. 2008;1655(September):a1655. Available from: http://www.bmj.com/lookup/doi/10.1136/bmj.a1655

19. Maidment ID, Aston L, Hilton A, Iqbal N, Child A, Shaw R. Role of community pharmacists in the use of antipsychotics for behavioural and psychological symptoms of dementia (BPSD): A qualitative study. BMJ Open. 2016;6(3).

20. Michie S, van Stralen MM, West R. The behaviour change wheel: A new method for characterising and designing behaviour change interventions. Implement Sci. 2011;6(1).

21. Michie S, Atkins L, West R. The Behaviour Change Wheel: a guide to designing interventions. London: Silverback Publishing; 2015.

22. Michie S, Ashford S, Sniehotta FF, Dombrowski SU, Bishop A, French DP. A refined taxonomy of behaviour change techniques to help people change their physical activity and healthy eating behaviours: The CALORE taxonomy. Psychol Heal. 2011;26(11):1479-98.

23. Dröes RM, Chattat R, Diaz A, Gove D, Graff M, Murphy K, et al. Social health and dementia: a European consensus on the operationalization of the concept and directions for research and practice. Aging Ment Heal [Internet]. 2017;21(1):4-17. Available from: http://dx.doi.org/10.1080/13607863.2016.1254596

24. Moniz-Cook E, Vernooij-Dassen M, Woods R, Verhey F, Chattat R, De Vugt M, et al. A European consensus on outcome measures for psychosocial intervention research in dementia care. Aging Ment Heal. 2008;12(1):14-29. 
25. National Institute for Health and Care Excellence (NICE). Dementia: supporting people with dementia and their carers in health and social care. 2017;(November 2006). Available from:

https://www.nice.org.uk/guidance/CG42/chapter/1-Guidance\#diagnosis-and-assessment-of-dementia

26. The dementia guide [Internet]. 2017. Available from:

https://www.alzheimers.org.uk/download/downloads/id/1881/the_dementia_guide.pdf

27. Cohen-Mansfield J. Nonpharmacologic Interventions for Inappropriate Behaviors in Dementia: A Review, Summary, and Critique. Am J Geriatr Psychiatry [Internet]. 2001 Sep 1 [cited 2017 Sep 27];9(4):361-81. Available from: http://www.sciencedirect.com/science/article/pii/S1064748112614511? showall\%3Dtrue\%26via\%3Dihub

28. O'Connor DW, Ames D, Gardner B, King M. Psychosocial treatments of behavior symptoms in dementia: a systematic review of reports meeting quality standards. Int Psychogeriatrics [Internet]. 2009;21(02):225. Available from: http://www.journals.cambridge.org/abstract_S1041610208007588

29. Teri L, Logsdon RG, Whall AL, Weiner MF, Trimmer C, Peskind E. Treatment for agitation in dementia patients: a behavior management approach. Psychotherapy. 1998;35:436-43.

30. Bandura A. human agency in social cognitive theory. Am Psychol. 1989;44(9):1175-84.

31. Hall GR, Buckwalter KC. Progressively lowered stress threshold: a conceptual model for care of adults with Alzheimer's disease. Arch Psychiatr Nurs. 1987;1:399-406.

32. Maslach C, Jackson SE, Leiter MP. Maslach Burnout Inventory [Internet]. 3rd Ed. Paolo Alto, CA: Consulting Psychologists Press; 1996. Available from: http://www.mindgarden.com/117-maslach-burnoutinventory\#horizontalTab3

33. O'Connor ML, McFadden SH. Development and Psychometric Validation of the Dementia Attitudes Scale. Int J Alzheimers Dis [Internet]. 2010;2010:1-10. Available from:

http://www.hindawi.com/journals/ijad/2010/454218/

34. Hoffmann TC, Glasziou PP, Boutron I, Milne R, Perera R, Moher D, et al. Better reporting of interventions: Template for intervention description and replication (TIDieR) checklist and guide. BMJ. 2014;348(March):1-12.

35. Tjia J, Hunnicutt JN, Herndon L, Blanks CR, Lapane KL, Wehry S. Association of a Communication Training Program With Use of Antipsychotics in Nursing Homes. 2017;177(6):846-53.

\section{Tables}

Table 1: Defining the Target Behaviour as Precisely as Possible: Responding to Challenging Behaviours as an Expression of Unmet Needs 


\begin{tabular}{|l|c|}
\hline Who needs to perform the behaviour? & Care staff, managers \\
\hline $\begin{array}{l}\text { What do they need to do differently to achieve } \\
\text { the desired effect? }\end{array}$ & $\begin{array}{l}\text { Develop problem-solving skills to identify } \\
\text { potential triggers }\end{array}$ \\
& $\begin{array}{l}\text { Get to know residents to identify potential } \\
\text { distraction techniques }\end{array}$ \\
& Try to prevent triggers from occurring \\
\hline When do they need to do it? & Every interaction with a resident \\
\hline Where do they need to do it? & In the resident's room, in common room areas \\
\hline How often do they need to do it? & Every interaction with a resident \\
\hline With whom do they need to do it? & All residents \\
\hline
\end{tabular}

Table 2: Defining the Target Behaviour as Precisely as Possible: Communicating with Compassion

\begin{tabular}{|l|l|}
\hline Who needs to perform the behaviour? & $\begin{array}{l}\text { Care staff, managers, support workers, } \\
\text { housekeeping staff }\end{array}$ \\
\hline $\begin{array}{l}\text { What do they need to do differently to achieve the } \\
\text { desired effect? }\end{array}$ & $\cdot$ Make eye contact \\
& $\cdot$ Speak directly to the person with dementia \\
& $\cdot$ Don't talk over the resident or ignore them \\
& - Minimise competing noise \\
\hline When do they need to do it? & Every interaction with a resident \\
\hline Where do they need to do it? & In the resident's room, in common room areas \\
\hline How often do they need to do it? & Every illeraction with a resident \\
\hline With whom do they need to do it? &
\end{tabular}

Table 3: Behavioural Analysis: Responding to Challenging Behaviour as an Expression of Unmet Need 


\begin{tabular}{|c|c|c|}
\hline COM-B components & $\begin{array}{l}\text { What needs to happen for the } \\
\text { target behaviour to occur? }\end{array}$ & $\begin{array}{l}\text { Is there a need for } \\
\text { change? }\end{array}$ \\
\hline $\begin{array}{l}\text { Physical Capability (physical skills, strength, } \\
\text { stamina) }\end{array}$ & $\begin{array}{l}\text { Staff need stamina to work } \\
\text { long shifts }\end{array}$ & $\begin{array}{l}\text { Unable to change } \\
\text { shift patterns } \\
\text { Need to provide a } \\
\text { supportive team } \\
\text { environment }\end{array}$ \\
\hline $\begin{array}{l}\text { Psychological Capability (knowledge or } \\
\text { psychological skills, strength or stamina to } \\
\text { engage in the necessary mental processes) }\end{array}$ & $\begin{array}{l}\text { Staff need: } \\
\text {. Problem-solving skills to } \\
\text { identify potential triggers } \\
\text {. Basic medical knowledge } \\
\text { to test for dehydration, } \\
\text { pain, urinary infection } \\
\text {. Knowledge of stimulation } \\
\text { techniques to avoid } \\
\text { agitation, boredom } \\
\text {. Problem-solving skills to } \\
\text { identify appropriate } \\
\text { distraction techniques } \\
\text { - Stamina to keep trying } \\
\text { when new techniques fail }\end{array}$ & $\begin{array}{l}\text { Some care staff } \\
\text { may have already } \\
\text { received training } \\
\text { but others may } \\
\text { not }\end{array}$ \\
\hline $\begin{array}{l}\text { Physical Opportunity (opportunity afforded by } \\
\text { the environment involving time, resources, } \\
\text { locations, cues, physical 'affordance') }\end{array}$ & $\begin{array}{l}\text { Staff need: } \\
\text {. } \begin{array}{l}\text { Resources to use with } \\
\text { residents, e.g. rummaging } \\
\text { boxes, life history, about } \\
\text { me books } \\
\text { - Appropriate staff:resident } \\
\text { ratios to ensure good } \\
\text { staffing levels } \\
\text { - Supervision } \\
\text { - Encouragement from } \\
\text { management and } \\
\text { colleagues }\end{array} \\
\end{array}$ & $\begin{array}{l}\text { Unable to change } \\
\text { staff:resident } \\
\text { ratios } \\
\text { Some managers } \\
\text { may be more } \\
\text { supportive than } \\
\text { others } \\
\text { It's always good to } \\
\text { boost morale so } \\
\text { colleagues can } \\
\text { support each other }\end{array}$ \\
\hline $\begin{array}{l}\text { Social Opportunity (opportunity afforded by } \\
\text { interpersonal influences, social cues and } \\
\text { cultural norms that influence the way we think } \\
\text { about things) }\end{array}$ & $\begin{array}{l}\text { Care homes need to: } \\
\text { - } \quad \text { Normalize this behaviour } \\
\text { among staff group } \\
\text { - Share good practice with } \\
\text { staff team }\end{array}$ & $\begin{array}{l}\text { Managers and } \\
\text { senior staff to role } \\
\text { model this } \\
\text { behaviour }\end{array}$ \\
\hline $\begin{array}{l}\text { Reflective Motivation (reflective processes } \\
\text { involving plans - self-conscious intentions - } \\
\text { and evaluations - beliefs about what is good } \\
\text { and bad) }\end{array}$ & $\begin{array}{l}\text { Make staff aware of their } \\
\text { own feelings and their } \\
\text { impact on residents } \\
\text { Help staff to be self-aware } \\
\text { and monitor their } \\
\text { behaviour in the moment } \\
\text { Separate the challenging } \\
\text { behaviour from the person } \\
\text { with dementia }\end{array}$ & $\begin{array}{l}\text { Staff need to } \\
\text { develop self- } \\
\text { awareness in their } \\
\text { practice }\end{array}$ \\
\hline Automatic Motivation (automatic processes & Staff need to want to: & - Staff need to be \\
\hline
\end{tabular}


involving emotional reactions, desires - wants and needs - impulses, inhibitions, drive states and reflex responses)
Find out the need behind the challenging behaviour

- Use problem-solving skills and individualized distraction techniques need to become second nature encouraged to take pride in their work

\section{Table 4: Behavioural Analysis: Communicating with Compassion}




\begin{tabular}{|c|c|c|}
\hline COM-B components & $\begin{array}{l}\text { What needs to happen for } \\
\text { the target behaviour to } \\
\text { occur? }\end{array}$ & Is there a need for change? \\
\hline $\begin{array}{l}\text { Physical Capability (physical skills, strength, } \\
\text { stamina) }\end{array}$ & $\begin{array}{l}\text { Staff need to be able to } \\
\text { speak with residents }\end{array}$ & $\begin{array}{l}\text { All staff are able to } \\
\text { communicate with } \\
\text { staff } \\
\text { Some staff may need } \\
\text { to change to be } \\
\text { compassionate in their } \\
\text { communication }\end{array}$ \\
\hline $\begin{array}{l}\text { Psychological Capability (knowledge or } \\
\text { psychological skills, strength or stamina to } \\
\text { engage in the necessary mental processes) }\end{array}$ & $\begin{array}{l}\text { Staff need: } \\
\text { Knowledge and } \\
\text { understanding of how } \\
\text { good communication } \\
\text { skills can help in } \\
\text { dementia care } \\
\text {. Skills in being } \\
\text { compassionate with } \\
\text { residents } \\
\text { To able to remain calm } \\
\text { when communicating } \\
\text { with residents }\end{array}$ & $\begin{array}{l}\text { Some care staff may } \\
\text { have already received } \\
\text { training but others may } \\
\text { not }\end{array}$ \\
\hline $\begin{array}{l}\text { Physical Opportunity (opportunity afforded by } \\
\text { the environment involving time, resources, } \\
\text { locations, cues, physical 'affordance') }\end{array}$ & $\begin{array}{l}\text { Staff need space and time } \\
\text { to pause and think about } \\
\text { their interactions with } \\
\text { residents }\end{array}$ & $\begin{array}{l}\text { We cannot change the } \\
\text { space but we can } \\
\text { encourage staff to use their } \\
\text { time differently }\end{array}$ \\
\hline $\begin{array}{l}\text { Social Opportunity (opportunity afforded by } \\
\text { interpersonal influences, social cues and } \\
\text { cultural norms that influence the way we think } \\
\text { about things) }\end{array}$ & $\begin{array}{l}\text { Care homes need to: } \\
\text {. Normalize this } \\
\text { behaviour }\end{array}$ & $\begin{array}{l}\text { Staff may need to think } \\
\text { about communication } \\
\text { differently }\end{array}$ \\
\hline $\begin{array}{l}\text { Reflective Motivation (reflective processes } \\
\text { involving plans - self-conscious intentions - } \\
\text { and evaluations - beliefs about what is good } \\
\text { and bad) }\end{array}$ & $\begin{array}{l}\text { Staff need to: } \\
\text { - } \quad \text { Be self-aware } \\
\text {. Manage their own } \\
\text { feelings } \\
\text { - Separate beliefs about } \\
\text { the person from the } \\
\text { dementia }\end{array}$ & $\begin{array}{l}\text { Staff may need help to } \\
\text { develop self-awareness }\end{array}$ \\
\hline $\begin{array}{l}\text { Automatic Motivation (automatic processes } \\
\text { involving emotional reactions, desires - wants } \\
\text { and needs - impulses, inhibitions, drive states } \\
\text { and reflex responses) }\end{array}$ & $\begin{array}{l}\text { Staff need to be personally } \\
\text { invested in the benefits to } \\
\text { residents of communicating } \\
\text { compassionately }\end{array}$ & $\begin{array}{l}\text { The benefits of } \\
\text { communicating with } \\
\text { compassion will need to be } \\
\text { introduced to care home } \\
\text { staff }\end{array}$ \\
\hline
\end{tabular}


Table 5: Behaviour Change Intervention: Inside Out

\begin{tabular}{|l|l|}
\hline $\begin{array}{l}\text { Description of the } \\
\text { intervention }\end{array}$ & "Inside Out": an interactive, three-hour training workshop \\
\hline Mode of delivery & $\begin{array}{l}\text { Face-to-face, in the care home setting, delivered by a Health Psychologist and research } \\
\text { assistant with experience of working in the Care Sector }\end{array}$ \\
\hline $\begin{array}{l}\text { Target } \\
\text { behaviours }\end{array}$ & $\begin{array}{l}\text { Responding to challenging behaviour as an expression of unmet need } \\
\text { Communicating with compassion }\end{array}$ \\
\hline $\begin{array}{l}\text { Functions of the } \\
\text { intervention } \\
\text { Behaviour } \\
\text { change } \\
\text { techniques }\end{array}$ & $\begin{array}{l}\text { Training, education, modelling, enablement } \\
\text { self-belief }\end{array}$ \\
\hline
\end{tabular}

\section{Figures}


Figure 1: Indicative content of the Inside Out intervention

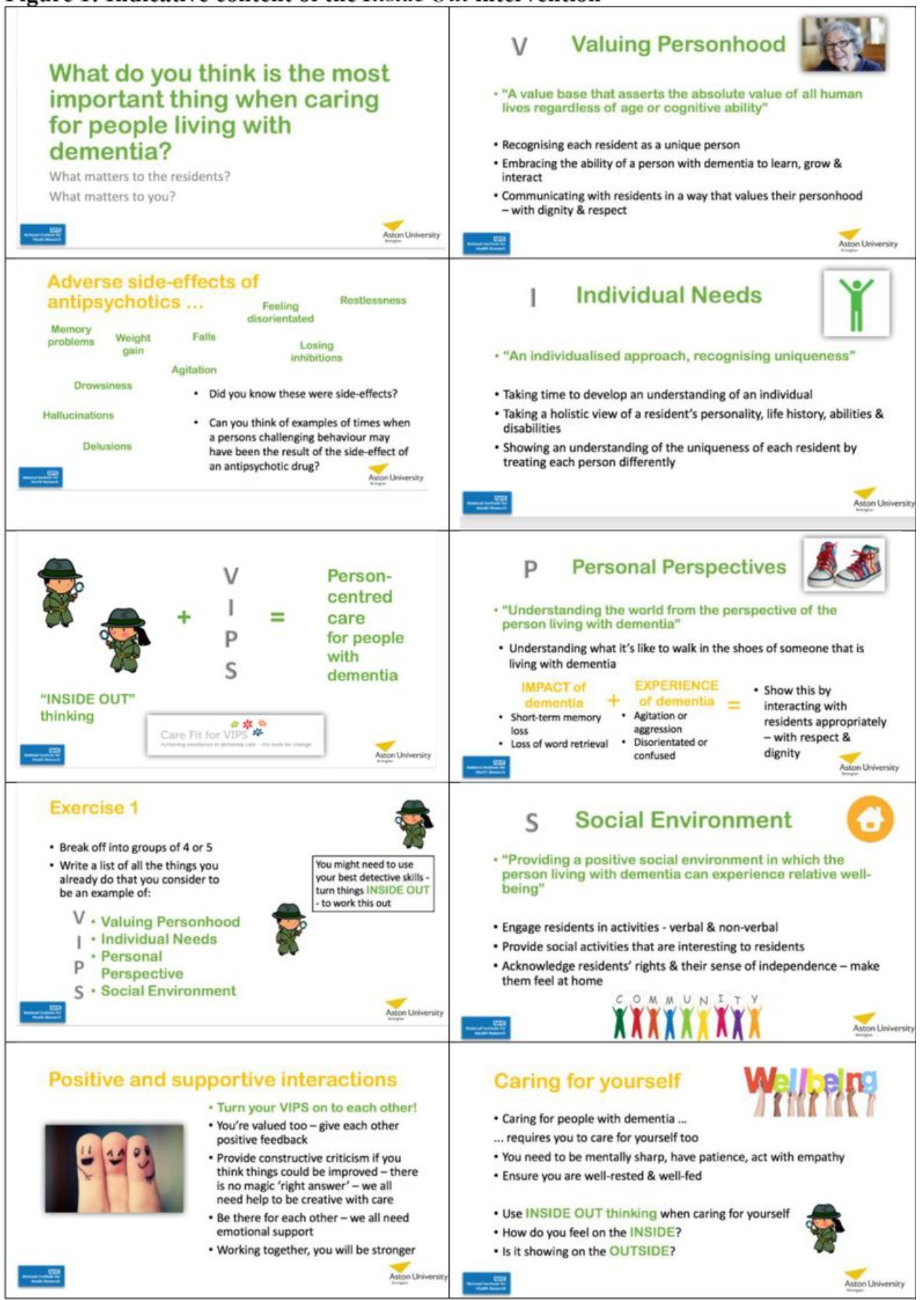

\section{Figure 1}

